\title{
ARCHITECTURE,
}

AN ARTIFICIAL

INTELLIGENCE

KRISTIAN

FASCHINGEDER

KRISTIAN FASCHINGEDER teaches at the Department of Architecture Theory and Philosophy of Technics (Technical University Vienna), the New Design University St. Pölten, and the FHCampus Vienna. In 2008-2010 he was a research assistant to the Chair of Design, Theory and History of Modern Architecture at the Bauhaus University Weimar, where he also received his $\mathrm{PhD}$ in 20II. In 20II-20I3 he curated the permanent science centre exhibition Sonnenwelt in Großschönau in Lower Austria. Numerous publications in architectural and theory journals. He has practised in Austrian and international architecture offices. 
In the foreword to his sixth book, Vitruvius tells the story of the pre-Socratic philosopher Aristippus of Cyrene, who was shipwrecked off the desert island of Rhodes and driven ashore. Though he didn't know where he was, he soon realized that this place had to be inhabited by humans: Geometric figures were drawn in the sand-unmistakably the traces of civilized people. Equipped with this knowledge, Aristippus set off for Rhodes to rush straight into the gymnasium, where he took part in the philosophical

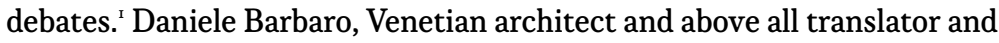
commentator of Vitruvius, later remarked on this story, that figures like those on the beach were rather the indisputable signs of higher thought. A footprint would have signified a human, but a triangle signified a mind. ${ }^{2}$

\section{ONCE AGAIN}

Ulysse runs ashore. Not a long time before Christ, but many years into the future. Not on a foreign coast, but on an alien planet: The protagonist Ulysse Mérou has been shipwrecked on the planet of the apes. The apes consider humans as we usually consider animals - some may possess intelligence but are not endowed with the faculty of reason. Ulysse is captured and locked in a cage, awaiting scientific research. Many long weeks pass by until Ulysse finds a way to convince Zira, one of the research apes of his faculty of reasoning: "Why hadn't I used this simple means before? Mustering my school-day memories, I drew the geometric figure illustrating the theorem Pythagoras." Now, the dam is broken:

Now it was she who appeared eager to establish contact. I gave thanks to Pythagoras and went a little further on the geometric track. On one side of the notebook I drew, the best I could, the three conic sections with their axes and focal points - an ellipse, a parabola and a hyperbola. Then I drew a circular cone on the opposite page. I remember here that the intersection of such a body by a plane produces one of the three conic sections, following to the angle of the cut. Now I demonstrated how an ellipse is created and pointed out the corresponding curve in my first drawing. The she-ape was amazed. She snatched the notebook out of my hands, drew a cone with another cutting plane and pointed to the hyperbola with her long finger. I was so moved that tears came to my eyes and I clasped Zira's hands. ${ }^{3}$

Ulysse, the French spaceman of the future, has succeeded. Not by some usual means of communication, not by learning a language, and not by

I Vitruvius, The Ten Books on Architecture, trans. by M. H Morgan (Cambridge: Harvard University Press, 1914), i67.

2 Werner Oechslin, 'Geometry and Line. Vitruvian Science and Architectural Drawing', Daidalos, I (1981), 20-35 (20-35, 27-28).

3 Pierre Boulle, La Planète des singes (Paris: Presses Pocket, I990), 88f (my translation); significantly, this form of communication does not occur in the movie. 
conveying a culturally conventional meaning, ${ }^{4}$ which might be stored in the immemorial memory of mankind, but definitely not in that of the apes. Rather, it was the mediation of geometric, abstract structures, a basis not of ours, but of the laws of nature. They do not come about through the agreement of like-minded people; rather, they are objective in a genuine sense. They always work; their truth content is demonstrable. Thus, even here, where nature and culture meet under inverted relations (ape: nature; man: culture), they remain the pivotal point of a communication that is, first of all, one thing: a form of translation.

That's interesting. When Barbaro, through Aristippus, deduces the presence of mind from the geometric figures in the sand, and Zira, the ape, deduces, from a conic section, the presence of mind in Ulysse, then it cannot actually be that of mankind alone. Man is not present at the drawn figure on the coast of Rhodes; neither a certain explanation nor the presence of humans is necessary. The figures and drawings act by themselves. Plans in architecture are no different. They enable the transfer of ideas from the planners to those who realize the construction. The presence of the architect is not required. Even if there are pragmatic reasons for this - anyone who can read plans should at least know what is meant by the drawings. The church of Saint-Pierre in Firminy by Le Corbusier, for example, whose construction began in I970, was not completed until forty-one years after the death of the architect, according to his plans. These also draw a simple geometric figure: The interior is formed by a square base that tapers upwards into a circle (initially at least). Daylight enters through light boxes and through a series of well-placed openings that relate to the constellation of Orion (by the way, that's where Ulysse went). The light boxes are designed so that on certain holidays, such as Good Friday and Easter Sunday, the altar is lit by the sun. The architecture here is a cosmic instrument that precisely measures the high holidays.

However, not every form of precision is necessary in order to be precise. The frontispiece by Michael Burghers certainly gets one thing wrong: What distinguishes geometric drawings is that they do not necessarily have to be drawn precisely in order to be correct. They do not need fixed quantities and numbers, but often deal with relations. ${ }^{5}$ Plato's Menon contains a demonstrative passage in which an uneducated servant reconstructs the diagonal of the square by 'remembering' it under the guidance of Socrates: ${ }^{6}$

4 Cf. the divergent approach of Ekkehard Drach, 'Architektur und Geometrie: zur Historizität formaler Ordnungssysteme' (Bielefeld: Transcript, 2012), 7f. For Drach, 'Architecture and inevitably the architectural form cannot be arbitrary, they are conventionally determined' (my translation). However, there are aspects that determine form that are not cultural, meaningful conventions, but structural in nature.

5 In the sense of proportions or relations. Ideally, geometric constructions only require a triangle and a compass.

6 Michel Serres, Les origines de la géométrie: tiers livre des fondations (Paris: Flammarion, 20II). Plato calls this recollection 'anamnesis'. 
In conversation with his pupil Meno, Socrates calls a young servant and draws a square in the sand. First, he makes sure that the boy knows that doubling one side of the square doubles its area, and if the other side too is doubled, the initial area quadruples. The boy also understands that doubling this square, of which a side length of two feet is assumed, results in an area of eight feet. However, the boy cannot answer the question of how large the edge length of the square must be in order to result in a square twice as large with a total area of eight feet. First, he tries it with a length of four feet: That gives an area of sixteen. Then he assumes a length of three feet: That makes an area of nine. Socrates demands of him a measure, the servant gives a quantity.7 Socrates now restates his questions: The boy should no longer start from the sides of the square, but from its diagonals. Now he understands how to get a square with the area of eight feet: One multiplies those triangles, which result from the diagonal division of the square. A triangle forms half of the square. But if you put four such triangles together, you get double the area: eight feet. The servant was limited in his thinking by calculating in whole numbers and by the arithmetic of multiplication tables which produce only natural numbers. It was only by thinking in geometric terms - and thus switching from quantitative to qualitative terms - that he was able to answer Socrates's question correctly. In the algebra of the Pythagoreans, only whole or rational numbers existed, but not the triangle with its irrational, therefore innumerable hypotenuse. ${ }^{8}$

FIGI

The philosopher Aristippos goes ashore on the island of Rhodes and deduces the presence of people from the geometric figures drawn in the sand.

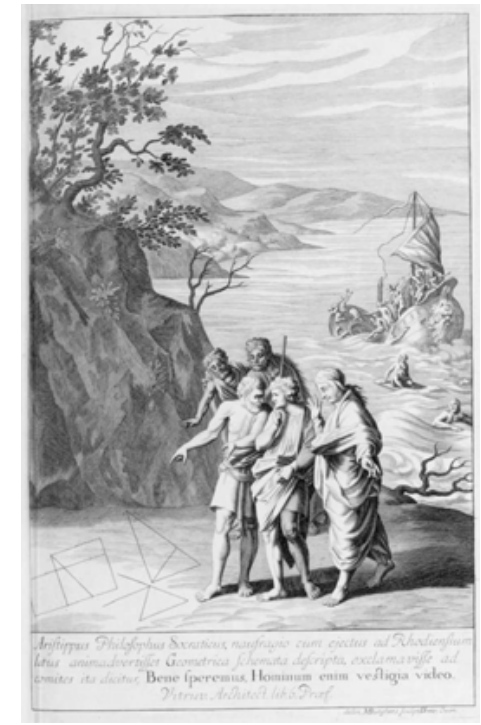

$7 \quad$ Ibid., 283.

8 Ibid., 279, 283, 285. 


\section{WHICH MIND?}

Aristippus is not the only one rushing from geometry to philosophy. Another, again a Frenchman, refers like no other to the implications of the dialogue in the Menon and to the evidence it contains. "There is no demonstration before the Greeks," says Michel Serres, none "before the apagogical proof, before geometry, before the irrational. [...] If you prefer not to make calculations, then show! This is an origin sentence." ${ }^{9}$ For Serres, the area makes things - lengths - visible, which the calculation could not capture. The proof (and the apagogical proof) demonstrates that numbers make things impossible that the surface makes possible as a matter of course. Another method to which Serres refers is used by Thales of Miletus to determine the height of the pyramids - without climbing or even touching the sacred tomb of the pharaoh. Instead, he uses a mediator, a stick, whose shadow at a certain moment of the day is as long as the stick itself. Measuring the shadow of the pyramid at the same time, he can tell how high it is. Of course, ancient Egypt could calculate the height of their pyramids, but Thales demonstrates the geometric similarity between the stick and the pyramid; between a length that is known and one that has to be found out. They're homothetic, because they have a common point of agreement (the sun), which in this case allows a translation from one object to another. Thales thus measures the relationship between the lengths of the shadows and at the same time invents the homothetia, and thus also the scaling and the scale. Serres designates both the side of the square from which Meno's servant proceeds in his calculations and the staff used by Thales as a gnomon. The term actually refers to the rod that casts the shadow on sundials from which the time of day can be read. Originally however - and for a very long time - this rod was used to determine the geographical latitude of a place, the northern direction, the equinoxes, the solstices and the ecliptic; it was not primarily a clock but an astronomical instrument.

In any case, Serres uses the term to designate tools that can be used to perform measurements within certain limits - whole numbers in the case of a servant whose gnomon is the side of the square; and a certain position of the sun at Thales, whose gnomon is the rod. This list could be extended at will. Examples by Serres himself are the 'gnomonic numbers' of Theon of Smyrna, or the Pascal triangle. Both are mathematical methods that are used to determine ongoing numbers. Euclid, in turn, calls in his Elements an L-shaped figure a gnomon, ${ }^{\mathrm{io}}$ and by this means the geometric abstraction of the right-angled carpenter's

9 Serres, Les origines de la géométrie, 28I; translation from the English edition: Michel Serres, Geometry: The Third Book of Foundations, trans. by Randolph Burks (London: Bloomsbury Academic, 2017), I7 I.

Io See Euclid, Stoicheia (Euclid's Elements), Book II, Explanations accessible at: https:// archive.org/details/euclidisoperaomnoreucluoft/page/n6 
angle of the same name. Called équerre in French, the relationship to the square (carré) and the sundial (cadran) is still present. Thus, instruments that originally drew the stations of the sun in the sand become tools that serve to depict abstract, geometric figures: The simple carpenter's square is replaced in geometry by the construction tools of the compass and ruler. The latter comes from the Latin term regula from rectus, the straight line, and at the same time also designates a rule. ${ }^{\text {II }}$ And the latter is what it's about, because with objects like these certain rules are set that allow or even dictate procedures. How should one define the gnomon differently, asks Serres, than as the law of a series? "The gnomon is defined as a law of construction, as the rule of a sequence or its engendering. An automatic rule, functioning all by itself." As a consequence, it only offers a limited set of possibilities. The servant calculates in his head, thinks in tables and remembers the multiplication tables. For Socrates and his school, this traditional tabular knowledge amounts to ignorance. Socrates, the philosopher who says he does not know, helps the servant to remember another knowledge and thus to free himself from his stencil-like tools of thought by leading him step by step, systematically and methodically, to the new, abstract world of geometry. A different thinking, a different knowledge; after Ulysse, the servant is the second person liberated by geometry.

The gnomon, Serres says, "functions all by itself, without any human intervention," like an artificial memory or an automaton. ${ }^{13}$ "The gnomon is thus intelligent in the literal sense of the word, since he puts together situations selected from thousands of others, and thus discerns and understands." ${ }^{14}$ An artificial intelligence: "Artificial intelligence doesn't date from yesterday," Serres emphasizes. "From the origin of science, there have existed things or states of affairs that the history of our languages has attributed to mental activities, as if these artefacts - plumb line, ruler or compass, framing square - passed for subjects of thought." ${ }^{15}$ For Serres there is therefore not only the recognizing subject, but also the intelligent artefact. His artificial intelligence stands for him independently next to what we commonly call intelligence when it is conceived as an ability that, at least until recently, was ascribed to man exclusively:

To name three automatisms by an identical name - that of the stake raised towards the sun, that of the framing square or the lateral band that's added or subtracted, and that of the operation

\footnotetext{
Serres, Les origines de la géométrie, 262.

Ibid., 263; English translation: Serres, Geometry, 163.

Ibid., 239; English translation Serres, Geometry, 133 .

Serres, Les origines de la géométrie, 246; My translation. For an alternate translation, see Serres, Geometry, I40.

Ibid., 264; My translation. For an alternate translation, see Serres, Geometry, 155.
} 
whose iteration constructs series of numbers-leads us to artificial intelligence. We see their avatars in these three states: first as thing, post or axis - a speculative tool - then as a ruler, that will at leisure reproduce straight lines, angles, ideal polygons, which are extracted from this rule, or better still abstracted from it, and finally as a formal operation on numbers; an automatic rule, an algorithm. ${ }^{16}$

So Serres identifies things - artefacts, rules, and mathematical tools - that think with, for, and beside us. It might be surprising that Serres finds this artificial intelligence not only in the algorithm-based technology of our days, but already in the ancient and simple artefacts whose sediments can be detected in our language, and whose traces lead to epistemology and philosophy. The undeniable signs of higher thinking that Daniele Barbaro recognizes in the figures Aristippus encounters on the beach of Rhodes are perhaps not only those of man. Man-made - they are: But things that act on their own, like automatons. Originated and developed at a certain time, through a local culture, they attain a universal claim. Our own thinking would not get far without them.

\section{RATIONALIZATION ACCORDING TO PLAN}

The Greeks were famous for their skill and resourcefulness. Serres notes that they invented a trick of the mind, the 'ruse-mathematics' [mathématique-ruse]: "They gave us systems and schemata that were so different from each other that, taking the Greeks at their word, we arranged them along a linear evolution." ${ }^{17}$ As an example, Serres cites two different political orders by means of which the historian Jean-Pierre Vernant traces the revolutionary changes in Greek culture. The forerunner is the strictly hierarchical organization of the archaic world, vertically organized and pyramid-shaped, with the ruler at the head. Innovative are the Greeks who organize themselves horizontally: They line up in a circle, and those who want to speak to the group stand in the middle, surrounded by their listeners. The hierarchy flattens out, with which the Greeks realized their famous isonomy, the democratic equality of rights. But it is not only society that organizes itself in a circular fashion; the same geometric figure also structures a new worldview: one that is no longer mythical and religious, but rational and geometric. The cosmos is organized similar to society, thereby losing its original, gradual structure: In the old order the gods are above, mortals in the middle, demons and other infernal beings below. In the new geometric order, the cosmos

I6 Ibid., 263; My translation. For an alternate translation, see Serres, Geometry, I53f.

I7 Serres, Les origines de la géométrie, 127; My translation. For an alternate translation, see Serres, Geometry, 49. 
loses its composition; ${ }^{18}$ it becomes a place that has neither floor nor ceiling, neither cellar nor attic, and thus loses its "fascinating quality as a phenomenological habitat." ${ }^{\text {19 }}$ Instead, indifference now prevails on the basis of equivalence through symmetry.

But it's not as clear-cut as Vernant claims, Serres replies. If one sees the archaic as elevation, and the Greek as plan view, the two schemata become connected to each other. It is the same model, equally symmetrical and organized according to the same plan. The only difference then is the mode of projection, which is rotated by a quarter. It is true that the Greeks disclose in the Agora those matters that concern the city, which suggests a desecration and rationalization of political life. The discussions of the Agora are based on the circular assembly, with a speaker in the centre and listeners on the periphery. At the end of his presentation, the speaker leaves the centre and moves to the edge, while a new speaker moves from the edge to the centre. Due to this symmetry and interchangeability, all are equal. The archaic city, on the other hand, is organized hierarchically, with the king at the head, who dominates the ruling class, which in turn dominates the submissive people. However, even in Greek society this equality only applies to the aristocracy. It is superior to the rest of the city; it forms a closed circle, and thus excludes all others: The height reverts into distance, which basically remains the same, regardless of whether it is vertically or horizontally oriented. What counts is the relationship to the centre, to the pole or the axis. The relationship of forces, formerly embodied by dominance, height and severity, is transformed into the concept of relationship, from the reference to the point of reference, as in a geometric representation. The hierarchy also remains in rational thinking, but there it becomes transparent and invisible, says Serres. In the moment we think rationally, we turn toward a centre, a reference system, an arché..$^{20}$ "The essential thing for the whole affair [...], remains the law of projective transformation, that quarter turn that makes one believe in democracy.".

The big difference between the archaic and Greek conceptions is not due to the principle of organization, but to the observer's point of view. There is a difference whether you look at something in the elevation or in the plan view. Both depict the same, but nobody sees, according to Serres, neither the world nor society as if they were looking at it from above. This position is above the king, it is that of the mind. In this way, things can be viewed from outside the world; now the universe can be thought of outside it. Already the practice of this drawing proves the

Note: This refers to the world view of Anaximander. see Serres, Geometry, 43.

Ibid., I23, I24f, I37.

Ibid., 126; My translation. For an alternate translation, see Serres, Geometry, 48. 
existence of another world. The Greeks invent in this way-and Serres sees this as the biggest cut-theory, a stage of vision-theoros means 'spectator'. They invent representation. From this vantage point, the world can be seen as a spectacle, as a theatre. “The Greeks' production is projection. And the optimization of a projecting site: the flyover from on high or from outside the world."

\section{MENON, WITHOUT SOCRATES}

It took a detour to get back to the plans of the architecture, in which much of what has been mentioned before can be found: The projection, the observation from above, which leads Le Corbusier to remark that everything starts from the plan view: "le plan est le générateur," he says in 1923 in Vers une Architecture. ${ }^{23}$ And perhaps architecture used the potential that the Greeks had discovered early on only so much later. While an architect such as Étienne-Louis Boullée-whom Le Corbusier admired-situates the educating effect of his architecture des ombres and architecture ensevelie (ink drawing is for him the appropriate way of depicting the monumental effect of light and shadow for his cenotaph for Newton [1784]) in the elevation, the power of architecture is later relocated into the ground plan, which is decomposed and analysed as diagrams; not least by protagonists such as Rudolf Wittkower, Bill Hillier and Michel Foucault. The comprehensible, visible and symbolic effect of a representative architecture is transferred into the sober, ornamentless ground plan, objectified and thus made quasi invisible. Although August Schmarsow considered architecture as 'space designer'-Raumgestalterin - and characterized the history of architecture as the "history of the sentiment of space," in which a "history of worldviews" was displayed, ${ }^{24}$ and the concept of architecture as an actual spatial art has persisted since, there has always been a clear conceptual separation between plan view and elevation. The representative character of architecture is manifest in the elevation, the organizational one in the ground plan. And while the difference between archaic and Greek worldviews is based on a simple twist, from the outline to the ground plan, in architecture the connection between these two forms of representation is still an absolute rarity until the 15 th century. ${ }^{25}$ see Serres, Geometry, $48 \mathrm{f}$.

23 My translation from the original: "Le plan est le générateur. Sans plan, il y a désordre, arbitraire. Le plan porte en lui l'essence de la sensation." Le Corbusier, Vers une architecture (Paris: G. Crès, 1925), 8.

24 see Fritz Neumeyer, Quellentexte zur Architekturtheorie (Munich: Prestel, 2002), 333.

25 see J Sakarovitch, Epures d'architecture: de la coupe des pierres à la géométrie descriptive XVI ${ }^{e}-X I X^{e}$ siècles (Basel: Birkhäuser, 1998), 45. 
That's remarkable. Throughout the Middle Ages, a system of proportions was sufficient to infer the object from the ground plan. Such a system required a very codified architecture whose proportions were extraordinarily repetitive. This was made possible by squaring, a system of doubling the area of the square (by means of the diagonal, of course), which, however, can only be proven in Gothic architecture at the end of the 15 th century (although Villard de Honnecourt was taking steps in this direction already in the 13 th century).$^{26}$ The architects of the Middle Ages could not cope well with leaps in scale. New projects were often copying an existing project, whose floor plan was then often simply enlarged. The list of cathedrals that collapsed during construction is long. They were closely observed during construction and, in the event of some deformation, reinforced as needed. One finds here a constant of medieval building practice: a purely empirical, step-by-step procedure of algorithmic thought, based on traditions as an almost artificial memory, but, on the other hand, always in search of new technical solutions. ${ }^{27}$ But without theory, without abstraction and without planning -in the sense of a forward concept, into the future-it is hardly possible to ask the right questions.

Once it has been understood that a great deal can be achieved with the abstraction of geometry, it becomes more obvious to transcend the existing limitations. By combining the two schemata of ground plan and outline into a coherent system of planning, a new form of geometric representation could emerge: "First I draw a rectangular square of any size on the surface to be painted; I assume that it is an open window through which I look at what is to be painted here," Alberti describes his construction of perspective space. ${ }^{28}$ This new space immediately serves another purpose: not planning, but above all the social role of architecture. For Alberti, the perspective is the prerequisite to provide for an action -an istoria - su luogo, its frame, space and place. It should not just be a neutral container, but already possess dramaturgical qualities. The perspectival construction is the necessary prerequisite for an event to unfold there.

At the same time, certain objects are excluded with this mode of representation. Hubert Damisch notices that such a perspective shall have only knowledge of those things it can set within its order: things which occupy a place and whose contour can be defined by a line. The first modern perspective, which its inventor Brunelleschi used with the help of his tavoletta (a small panel), is a theoretical demonstration: It shows that the vanishing point coincides with the point of view. ${ }^{29}$ Brunelleschi

26 Sakarovitch, 4I.

27 J.-M Savignat, Dessin et architecture du Moyen Age au XVIIIe siècle (Paris: Ecole nationale supérieure des beaux-arts, I983), 30.

28 Leon Battista Alberti, Über die Malkunst = Della pittura, trans. by Oskar Bätschmann and Sandra Gianfreda (Darmstadt: WBG, 2013), 93.

29 see Hubert Damisch, Théorie du nuage: pour une historie de la peinture. (Paris: Éditions du Seuil, 1972), 157, 170. 
will not depict heaven but show it by means of a mirror. A clear limitation of the construction to its possibilities; for what the mirror shows is what the geometric means cannot cover. The sky occupies no place, it has no measure; and as far as clouds are concerned, they do not allow for fixed contours, nor for their forms to be examined with regard to their surfaces. The cloud belongs to the 'bodies without surface', as Leonardo will write later, bodies that have neither a precise form nor extremities and whose boundaries penetrate each other. Clouds cannot be captured by the method of perspective, but Leonardo will nonetheless deal with them: To get closer to nature, and to combine in the painting quantities with qualities. ${ }^{30}$

First the clouds, then architecture: As Robin Evans writes, the classic building was axially-symmetric. ${ }^{31}$ An ideal centre line represented as much the plane of symmetry as the plane of the most advantageous section, which does not just lead through a cavity (because it makes little sense otherwise), but also runs through the apex of a vault. This line then corresponds to the development axis of the building, which manifests on the main façade through a centred entrance. For a sufficient representation of such a building, three drawings are sufficient: Floor plan, outline and section. However, Hans Scharoun almost failed with these given means: the Berlin Philharmonie (completed in I963) does not have a main façade; it is neither rectangular nor symmetrical, nor does it have a central axis. It was mostly designed through models and sketches. The usual drawings were supplemented by large-scale sections that cover the entire building at close intervals in order to gain a reliable overview and control of the project. Although the two published sections through the auditorium provide a fair description of the interior, they are insufficient to describe the geometry of its bevelled and curved surfaces more precisely. For the execution, the traditional cut was compressed to such an extent, that in fact a profile was created with which the building was cut into thin slices. Perhaps this was a short-sighted approach, less tied to experience than the classic cut, and anything but economic. Nor was it suitable for describing the geometric properties of the outer skin..$^{32}$ Nevertheless, this building embodies a fundamental virtue of architecture: It is not conformity to the available means that distinguishes it, not appropriateness, but rather exuberance and excess; the transgression of what Serres calls the gnomon. This Architecture went ahead of its plans.

Ibid., 218, footnote 4; "And just as music and geometry take into account the relationships of constant magnitudes, and arithmetic the relationships of unsteady ones, so painting subjects all constant magnitudes to contemplation, and in addition the qualities of relationships, of shadows and lights, and of distances, in their perspective." After: Leonardo Da Vinci, Traktat von der Malerei, trans. by Heinrich Ludwig and Marie Herzfeld (Jena, I909), 32.

3I Robin Evans, The Projective Cast: Architecture and Its Three Geometries (London: MIT Press, 1995), irgff.

32 Ibid., I20. 
